Tropical Journal of Pharmaceutical Research March 2020; 19 (3): 497-503

ISSN: $1596-5996$ (print); 1596-9827 (electronic)

(C) Pharmacotherapy Group, Faculty of Pharmacy, University of Benin, Benin City, 300001 Nigeria.

Available online at http://www.tjpr.org

Original Research Article

http://dx.doi.org/10.4314/tjpr.v19i3.6

\title{
Bisleuconothine A protects periodontal tissue via the regulation of RANKL expression and infiltration of inflammatory cells
}

\author{
Fang Wang ${ }^{1,2}$, Ping Sun ${ }^{1,2}$, Qiang Sun ${ }^{1,2 *}$ \\ ${ }^{1}$ Department of Periodontics, The Affiliated Stomatology Hospital, Zhejiang University School of Medicine, ${ }^{2}$ Key Laboratory of \\ Oral Biomedical Research of Zhejiang Province, Zhejiang University School of Stomatology, Hangzhou, Zhejiang 310000, \\ China
}

*For correspondence: Email: ShannonMorsenbx@yahoo.com; Tel: 0086-0571-88198559

Sent for review: 18 May 2019

Revised accepted: 21 February 2020

\begin{abstract}
Purpose: To investigate the protective effect of bisleuconothine $A$ on periodontal tissue in rats and the mechanism involved.

Methods: Adult male Sprague Dawley rats $(n=32)$ weighing $180-200 \mathrm{~g}$ (mean weight, $190 \pm 10 \mathrm{~g}$ ) were randomly assigned to four groups of eight rats each: control group, periodontitis group, bisleuconothine A $(50 \mathrm{mg} / \mathrm{kg})$ group and bisleuconothine $A(100 \mathrm{mg} / \mathrm{kg})$ group. Rats in the treatment groups received bisleuconothine intraperitoneally for two weeks. Periodontitis was induced in the rats using standard procedures. Serum and tissue samples were used for biochemical analysis. Alveolar bone loss was measured in rat maxillae, while the activity of bone alkaline phosphatase (BALP) was determined in serum. Tumor necrosis factor $\alpha$ (TNF- $\alpha$ ) interleukin-1 $\beta$ and interleukin-6 (IL-1 $\beta$ and IL-6) were determined in gingival tissue using enzyme-linked immunosorbent assay (ELISA) kit. Gene and protein expressions of receptor activator of nuclear factor kappa-B ligand (RANKL), osteoprotegerin (OPG), and matrix metallopeptidase-9 (MMP-9) were measured in gingival tissue using real-time quantitative polymerase chain reaction ( $Q R T-P C R)$ and Western blotting, respectively.

Results: Bisleuconothine $A$ treatment significantly and dose-dependently reduced alveolar bone loss, as well as serum levels of TNF- $\alpha, I L-1 \beta$ and IL-6, but increased BALP activity in periodontitis rats ( $p<$ 0.05 ). It also significantly and dose-dependently reduced mRNA expressions of RANKL and MMP-9, but significantly increased OPG mRNA expression $(p<0.05)$. Similarly, treatment with bisleuconothine $A$ significantly and dose-dependently down-regulated RANKL, $p-N F-k B, p-l k B a$ and iNOS proteins in gingival tissue of periodontitis rats $(p<0.05)$. The results of histopathological examination indicated that bisleuconothine A treatment significantly reversed histological changes in periodontal tissues of periodontitis rats. It also significantly reduced the degree of polymorphonuclear (PMN) cell infiltration in periodontal tissue.

Conclusion: The results obtained show that bisleuconothine A protects periodontal tissue via the regulation of RANKL expression and infiltration of inflammatory cells.
\end{abstract}

Keywords: Bisleuconothine A, Expression, Inflammation, Periodontitis, RANKL

This is an Open Access article that uses a fund-ing model which does not charge readers or their institutions for access and distributed under the terms of the Creative Commons Attribution License (http://creativecommons.org/licenses/by/4.0) and the Budapest Open Access Initiative (http://www.budapestopenaccessinitiative.org/read), which permit unrestricted use, distribution, and reproduction in any medium, provided the original work is properly credited.

Tropical Journal of Pharmaceutical Research is indexed by Science Citation Index (SciSearch), Scopus, International Pharmaceutical Abstract, Chemical Abstracts, Embase, Index Copernicus, EBSCO, African Index Medicus, JournalSeek, Journal Citation Reports/Science Edition, Directory of Open Access Journals (DOAJ), African Journal Online, Bioline International, Open-J-Gate and Pharmacy Abstracts 


\section{INTRODUCTION}

Periodontitis is a chronic inflammatory and infectious disease in which the integrity of gum tissue is disrupted [1]. Inflammation-induced damage to gum connective tissues reduces the anchoring ability of the teeth and may lead to tooth loss [2]. Environmental and genetic factors contribute significantly to periodontal disease via alterations in inflammatory/immune responses [3]. Studies have shown that inflammatory cytokines such as IL- 6 and IL- 8 activate matrix metalloproteinases (MMPs), thereby promoting osteoclastogenesis [4]. Receptor activator of nuclear factor kappa-B ligand (RANKL), also known as tumor necrosis factor ligand superfamily member 11 , tumor necrosis factor (TNF)-related activation-induced cytokine, OPG ligand or osteoclast differentiation factor, regulates cell proliferation by modifying Id4, Id2 and cyclin D1 protein levels. In humans, it is encoded by the TNFSF11 gene. On binding to its receptor, RANKL induces osteoclastogenesis [5]. The binding of RANKL to OPG reduces its activity. Osteoclastogenesis is regulated by maintaining RANKL/OPG ratio. Studies have shown that cytokines decrease OPG expression, thereby stimulating RANKL and ultimately tooth loss [6].

Although surgery and mechanical therapy are used for the management of periodontal disease, they are however ineffective. Adjuvant therapies such as non-steroidal anti-inflammatory drugs (NSAIDs) and antibiotics are also used for the treatment of periodontitis. Their clinical application is however limited due to some setbacks. Thus, the development of new therapeutic approaches for effective management of periodontitis has become necessary. Over the last few decades, alternative medicine has shown great potential in the treatment of several diseases including periodontitis.

Bisleuconothine $A$ is a bisindole alkaloid isolated from Leuconotis griffithii [7]. Bisindole alkaloids have received considerable attention for their potential biological properties, including antitumor, antimalarial, anti-inflammatory and antibacterial effects [8-11]. The antitumor effect of bisleuconothine $A$ is exerted via Wnt and AKT/mTOR signaling pathways [12]. These pathways are regulated by inflammatory cytokines [13]. Bisleuconothine A regulates these pathways via modulation of cytokine expressions. This study investigated the protective effect of bisleuconothine $A$ on periodontal tissue in rats and the mechanism involved.

\section{EXPERIMENTAL}

\section{Rats}

Adult male Sprague Dawley rats weighing 180 $200 \mathrm{~g}$ (mean weight, $190 \pm 10 \mathrm{~g}$ ) were used for this study. They were housed in metal cages under standard conditions and had free access to standard feed and water. The rats were exposed to 12-h light/12-h dark cycle, and maintained at a temperature of $25{ }^{\circ} \mathrm{C}$ and $65 \%$ humidity. The rats were acclimatized to the laboratory conditions for one week prior to commencement of the study. The study protocol was approved by the Institutional Animal Ethics Committee of Stomatology Hospital, Zhejiang University School of Medicine, China (approval no. IAEC/SH/ZUSM/2017/08), and the study procedures were carried out according to the guidelines of the International Association for the Assessment and Accreditation of Laboratory Animal Care (AAALAC) [14].

\section{Experimental design}

The rats ( $n=32$ ) were randomly assigned to four groups of eight rats each: control group, periodontitis group, bisleuconothine A $(50$ $\mathrm{mg} / \mathrm{kg}$ bwt) group and bisleuconothine A (100 $\mathrm{mg} / \mathrm{kg}$ bwt) group. Rats in the treatment groups received bisleuconothine intraperitoneally for two weeks.

\section{Preparation of rat model of periodontitis}

Periodontitis was induced in the rats using standard procedures [15]. The rats were anesthetized via intraperitoneal administration of $50 \mathrm{mg} / \mathrm{kg}$ bwt pentobarbital and a suture was made around each cervix of the first molar (M1) on bilateral sides in the maxilla in the open mouth, using Hashimoto's gag. Mesial site of M1 was knotted with the suture, but in control group M1 was not ligated with the suture.

\section{Blood sample collection}

At the end of the $14^{\text {th }}$ day, the rats were fasted overnight and euthanized. Blood was collected from the rats via cardiac puncture and centrifuged at $3000 \mathrm{rpm}$ for $10 \mathrm{~min}$ to obtain serum. The excised bone tissue and serum were used for biochemical analysis.

\section{Determination of BALP activity}

Total alkaline phosphatase (ALP) activity was determined in rat serum using ALP assay kit. 
Aliquot of serum was subjected to thermoactivation for $10 \mathrm{~min}$ at $56^{\circ} \mathrm{C}$, and ALP activity was measured in the heated serum. The activity of BALP was obtained by taking the difference between ALP activities in unheated serum and heated serum.

\section{Determination of alveolar bone loss}

Maxillae isolated from the rats were stained with $1 \%$ methylene blue after an initial fixation in 10 $\%$ formalin solution. Bone loss was determined by measuring the length of each molar. Alveolar bone loss was estimated using sum of the measurements from buccal tooth surfaces and the difference between the values of the right maxilla and those of left maxilla. Imaging software was then used to measure the distance, and standardized digital photography was used for the morphometric analysis of alveolar bone.

\section{Assessment of levels of cytokines in gingival tissue}

Gingival tissues were isolated from each rat and homogenized with phosphate buffer using mechanical homogenizer. Levels of IL-1 $1 \beta$, IL-6 and TNF- $\alpha$ were determined in the resultant tissue homogenate using ELISA kit.

\section{Quantitative real-time polymerase chain reaction (qRT-PCR)}

The mRNA levels of OPG, RANKL, and MMP-9 were determined in gingival tissue using qRTPCR. Each tissue was trypsinized using 0.05 trypsin and the resultant cell suspension was subjected to qRT-PCR. Trizol RNA extraction reagent was used to extract total RNA from cells of each group, while cDNA synthesis kit was used to perform cDNA synthesis reaction according to the instructions of the manufacturer. Light Cycler 1536 RT-PCR detection system was used for the estimation of the mRNA expressions of the genes. Variation in the cDNA content was normalized using $\beta$-actin. The PCR reaction mixture $(20 \mu \mathrm{L})$ consisted of $6.4 \mu \mathrm{L}$ of $\mathrm{dH}_{2} \mathrm{O}, 1.6$ $\mu \mathrm{L}$ of gene-specific primer $(10 \mu \mathrm{M}), 2 \mu \mathrm{L}$ of synthesized cDNA and $10 \mu \mathrm{L}$ of SYBR Premix Ex Taq ${ }^{\mathrm{TM}}$ II. The Ct value of U6 was taken as the internal parameter, and $2^{-\Delta \Delta C t}$ was used to calculate the relative expression levels of the proteins.

\section{Western blotting}

The cell suspension was washed with phosphate-buffered saline (PBS) and NP40 protein lysis buffer was used to lyse the cells. The lysate was centrifuged at $12,000 \mathrm{rpm}$ for 10 min at $4{ }^{\circ} \mathrm{C}$, and the protein concentration of the supernatant was determined using DC protein assay kit. A portion of total cell protein $(30 \mu \mathrm{g})$ from each sample was separated on $10 \%$ sodium dodecyl sulphate (SDS)-polyacrylamide gel electrophoresis and transferred to a fixed polyvinylidene fluoride membrane at $110 \mathrm{~V}$ and $90^{\circ} \mathrm{C}$ for $120 \mathrm{~min}$. Subsequently, non-fat milk powder (3\%) in Tris-buffered saline containing $0.2 \%$ Tween-20 (TBS-T) was added with gentle shaking at $37{ }^{\circ} \mathrm{C}$ and incubated to block nonspecific binding of the blot. Incubation of the blots was performed overnight at $4{ }^{\circ} \mathrm{C}$ with primary antibodies of RANKL, iNOS, IkB- $\alpha, N F-k B$ and $\beta-$ actin, each at a dilution of 1 to 1000 . Then, the membrane was washed thrice with TBS-T and further incubated with horseradish peroxidaseconjugated goat anti-rabbit IgG secondary antibody for $1 \mathrm{~h}$ at room temperature. The blot was developed using an X-ray film. Grayscale analysis of the bands was performed using Biorad gel imaging system. The respective protein expression levels were normalized to that of $\beta$ actin which was used as a standard.

\section{Histopathological examination of gingival tissue}

Tissue specimen from rat molars was separated out and fixed in $10 \%$ formalin solution. It was subsequently treated for a period of four weeks with EDTA to allow for decalcification. The tissue was thereafter embedded in paraffin. Serial sections, each of $4 \mu \mathrm{m}$ thickness, were made using a microtome and stained with hematoxylin and eosin according to standard method, and examined under light microscope. Different tissue regions were selected with the help of morphometric lens in $0.25 \mathrm{~mm}^{2}$ microscopic field, and the mean was calculated. ImageJ image analysis software was used to determine the infiltration of inflammatory PMN cells into the gingival tissue of periodontitis rats.

\section{Statistical analysis}

Data are expressed as mean \pm SD. Statistical analysis was performed using GraphPad prism (version 6.1). Groups were compared using Student's t-test. Statistical significance was assumed at $p<0.05$.

\section{RESULTS}

\section{Effect of bisleuconothine A on alveolar bone loss}

As shown in Figure $1 \mathrm{~A}$ and $\mathrm{B}$, treatment with bisleuconothine $A$ significantly and dose- 
dependently reduced alveolar bone loss in periodontitis rats $(p<0.05)$.

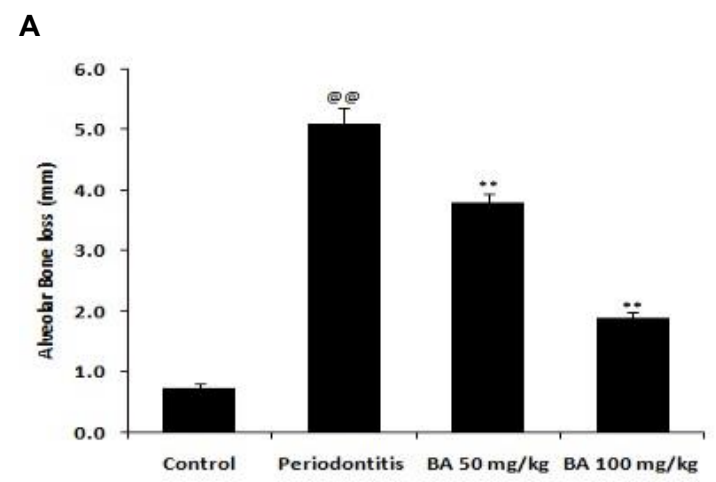

B

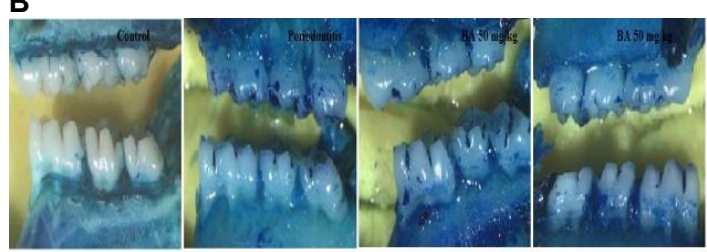

Figure 1: Alveolar bone loss in periodontitis rats. (A): Analysis of alveolar bone loss; (B): Morphometric observation of alveolar bone. @@p $<0.05$, when compared with control group; ${ }^{* *} p<0.05$, when compared with periodontitis group

\section{Activity of BALP}

Bisleuconothine $A$ treatment significantly and dose-dependently increased the activity of BALP in periodontitis rats $(p<0.05$; Figure 2$)$.

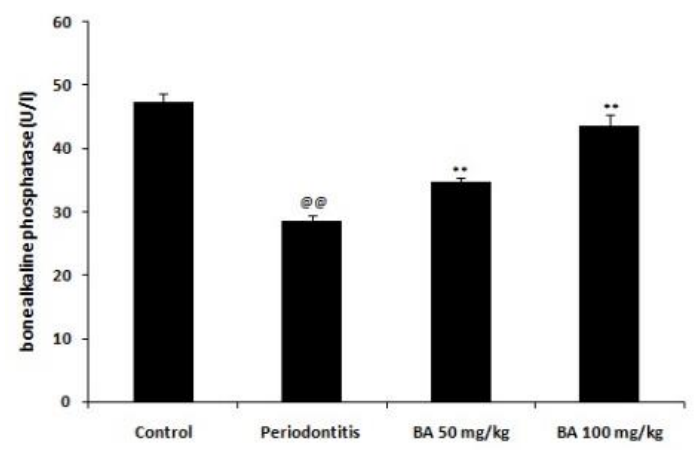

Figure 2: Effect of bisleuconothine A on BALP activity; $@ @ p<0.05$, when compared with control group; ${ }^{* *} p<$ 0.05 , when compared with periodontitis group

\section{Effect of bisleuconothine $A$ on levels of cytokines in serum of periodontitis rats}

Treatment with bisleuconothine A significantly and dose-dependently reduced the levels of TNF- $\alpha, I L-1 \beta$ and IL- 6 in serum of periodontitis rats $(p<0.05)$. These results are shown in Figure 3 A - C.

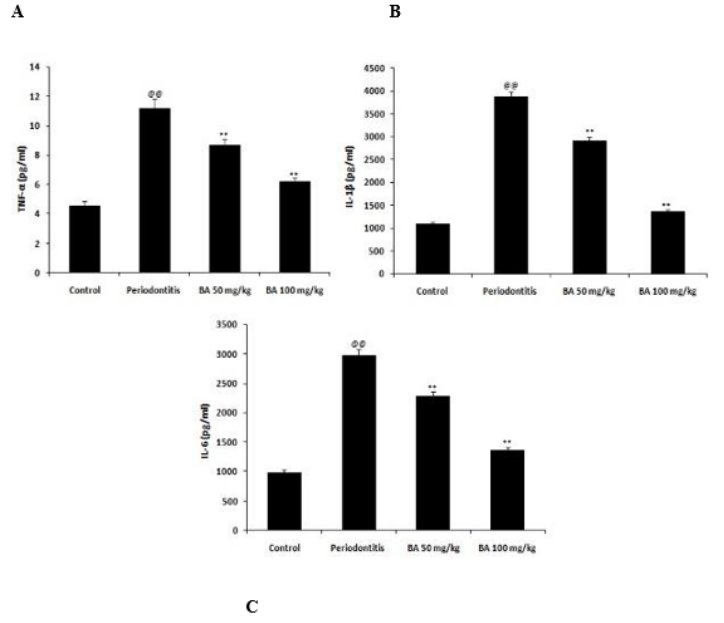

Figure 3: Levels of inflammatory cytokines in serum of periodontitis rats. (A): Level of TNF- $\alpha$ in serum of periodontitis rats; (B): Level of IL-1 $\beta$ in serum of periodontitis rats; (C): Level of IL-6 in serum of periodontitis rats; @@ $p<0.05$, when compared with control group; ${ }^{* *} p<0.05$, when compared with periodontitis group

Levels of expression of RANKL, OPG and MMP-9 in periodontitis rats

Bisleuconothine A treatment significantly and dose-dependently reduced mRNA expressions of RANKL and MMP-9, but significantly increased OPG mRNA expression ( $p<0.05$; Figure 4$)$.

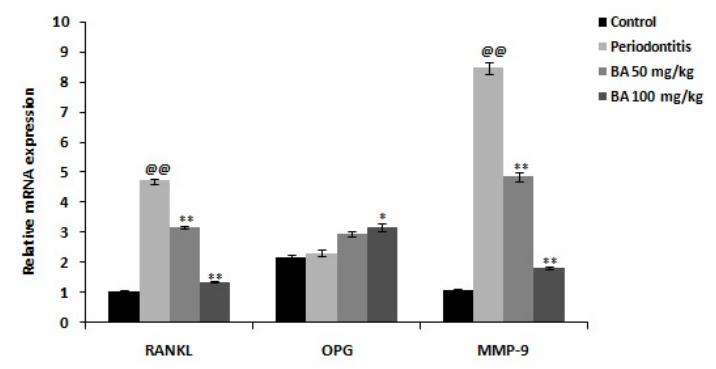

Figure 4: Effect of bisleuconothine $A$ on mRNA expressions of RANKL, OPG and MMP-9 in gingival tissue of periodontitis rats; $@ @ p<0.05$, when compared with control group; ${ }^{* *} p<0.05$, when compared with periodontitis group

Protein expressions of RANKL, p-NF-kB, pIkBa and iNOS in gingival tissue of periodontitis rats

As shown in Figure 5, treatment with bisleuconothine A significantly and dosedependently down-regulated the protein expressions of RANKL, $p-N F-k B, p-l k B \alpha$ and iNOS in gingival tissue of periodontitis rats $(p<$ 0.05). 


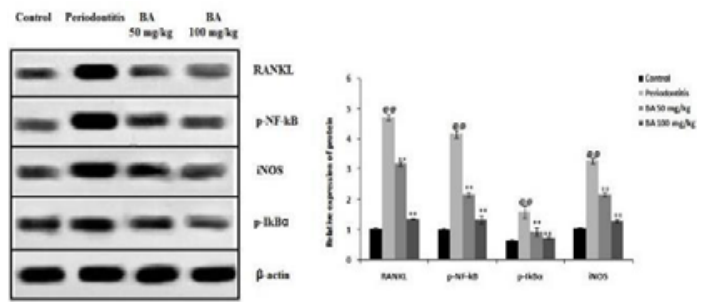

Figure 5: Effect of bisleuconothine $A$ on the expressions of RANKL, $p-N F-k B, p-l k B a$ and iNOS proteins in gingival tissue of periodontitis rats. $(A)$ : Protein expressions of RANKL, p-NF-kB, p-lkBa and iNOS as measured using Western blotting; (B): Protein expressions of RANKL, p-NF-kB, p-lkB $\alpha$ and iNOS as measured using qRT-PCR; @@ $p<0.05$, when compared with control group; ${ }^{* *} p<0.05$, when compared with periodontitis group

\section{Histological changes in molar tissues of} periodontitis rats

There was significant alteration in the architecture of connective tissue of periodontitis rats. The number of $P M N$ cells infiltrating the periodontal tissue of periodontitis rats was significantly increased, when compared with control group rats. However, bisleuconothine A treatment significantly reversed histopathological changes in periodontal tissues of periodontitis rats.

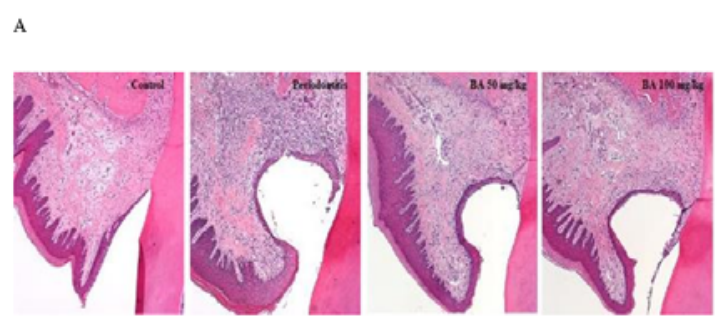

B

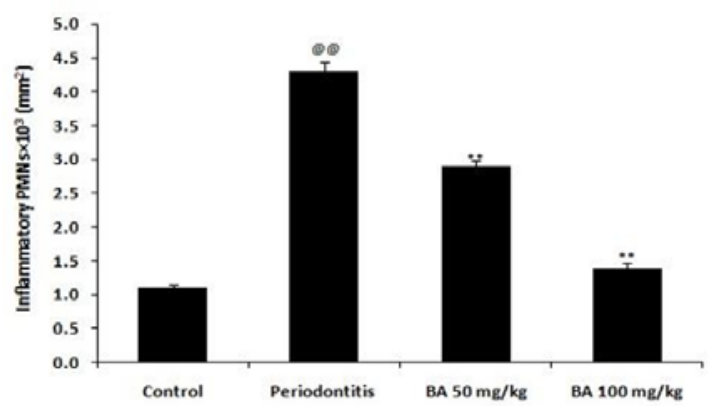

Figure 6: Effect of bisleuconothine $A$ on the histology of molar tissues of periodontitis rats. (A): Histopathology of molar tissues; (B): Quantitative analysis of total number of PMN cells in molar tissues. $@ @ p<0.05$, when compared with control group; ${ }^{* *} p<$ 0.05 , when compared with periodontitis group

\section{DISCUSSION}

Periodontitis is a chronic inflammatory disorder caused by an imbalance between host defense mechanism and subgingival microbiota [16]. It refers to inflammation of gums and supporting structures of the teeth. It is one of the most common human diseases. Periodontitis is caused by certain bacteria (known as periodontal bacteria) and by the local inflammation triggered by them.

The available treatment option for periodontitis is associated with several limitations. This study investigated the protective effect of bisleuconothine $A$ on periodontal tissue in rats and the mechanism involved.

In periodontitis, translocation of immune cells to the periodontal tissue promotes the release of inflammatory cytokines [17]. Cytokines such as $\mathrm{IL}-1 \beta$ and TNF- $\alpha$ participate in collagen degradation and bone resorption by activating collagenolytic enzymes and osteoclasts [18]. Reduction in cytokine levels has been shown to prevent/delay periodontitis. Thus, antiinflammatory drugs are normally used for its treatment.

In this study, bisleuconothine A treatment significantly and dose-dependently reduced the levels of inflammatory cytokines in gingival tissue of periodontitis rats. In periodontitis, gingival tissues are destroyed due to increased secretion of IL-6 and TNF- $\alpha$, a process mediated by RANKL/OPG [19]. It has been reported that in periodontitis, the expression of RANKL is increased, while that of OPG is reduced in gingival tissue, with subsequent tooth loss [20]. In this study, bisleuconothine A treatment significantly reversed the altered expressions of OPG and RANKL in gingival tissue of periodontitis rats. These results are in agreement with those of previous studies $[19,20]$. The results of histopathological examination which showed that bisleuconothine A treatment significantly reversed histological changes in periodontal tissues of periodontitis rats provided supportive evidence for results from biochemical assays. The treatment also significantly reduced the degree of PMN cell infiltrating in the periodontal tissue.

Oxidative stress has also been implicated in the pathogenesis of periodontitis [21]. The results of this study showed that bisleuconothine $A$ treatment significantly and dose-dependently down-regulated the protein expressions of RANKL, $p-N F-k B, p-l k B \alpha$ and iNOS in gingival tissue of periodontitis rats. 


\section{CONCLUSION}

The results obtained in this study show that bisleuconothine A protects periodontal tissue via the regulation of RANKL expression and infiltration of inflammatory cells. Thus, bisleuconothine A may have clinical application in the treatment of periodontitis.

\section{DECLARATIONS}

\section{Acknowledgement}

The authors are thankful to Zhejiang Natural Resources Fund Youth Fund (no. LQ14H140003) and Zhejiang medical and health science and technology project (no. 2020386978), China for providing the funds for this work.

\section{Conflict of interest}

No conflict of interest is associated with this study.

\section{Contribution of authors}

We declare that this work was done by the authors named in this article and all liabilities pertaining to claims relating to the content of this article will be borne by the authors. Fang Wang conducted the experimental work and literature review related to presented work. Ping Sun perform the statistical analysis, and Qiang Sun supervised the presented work and written the manuscript.

\section{Open Access}

This is an Open Access article that uses a funding model which does not charge readers or their institutions for access and distributed under the terms of the Creative Commons Attribution License (http://creativecommons.org/licenses/by/ 4.0) and the Budapest Open Access Initiative (http://www.budapestopenaccessinitiative.org/rea d), which permit unrestricted use, distribution, and reproduction in any medium, provided the original work is properly credited.

\section{REFERENCES}

1. How KY, Song KP, Chan KG. Porphyromonas gingivalis: An Overview of Periodontopathic Pathogen below the Gum Line. Front Microbiol 2016; 7: 53.
2. Di Benedetto A, Gigante I, Colucci S, Grano M. Periodontal disease: linking the primary inflammation to bone loss. Clin Dev Immunol2013; 2013: 503754.

3. Cekici A, Kantarci A, Hasturk H, Van Dyke TE. Inflammatory and immune pathways in the pathogenesis of periodontal disease. Periodontol 2014; 64(1): 57-80.

4. Amarasekara DS, Yu J, Rho J. Bone Loss Triggered by the Cytokine Network in Inflammatory Autoimmune Diseases. J Immunol Res 2015; 2015: 832127.

5. Boyce BF, Xing L. Functions of RANKL/RANK/OPG in bone modeling and remodeling. Arch Biochem Biophys 2008; 473(2): 139-146.

6. Kohli SS, Kohli VS. Role of RANKLRANK/osteoprotegerin molecular complex in bone remodeling and its immunopathologic implications. Ind J Endocrinol Metab 2011;15(3):175-181.

7. Hirasawa $Y$, Shoji $T$, Arai $T$, Nugroho $A E$, Deguchi J, Hosoya $T$, Uchiyama N, Goda Y, Awang $K$, Hadi AH, Shiro $M$, Morita $H$. Bisleuconothine $A$, an eburnaneaspidosperma bisindole alkaloid from Leuconotis griffithii. Bioorg Med Chem Lett 2010; 20(6): 2021-2024.

8. Sim DS, Chong KW, Nge CE, Low YY, Sim KS, Kam TS. Cytotoxic vobasine, tacaman, and corynanthetryptamine bisindole alkaloids from Tabernaemontana and structure revision of tronoharine. J Nat Prod 2014; 77: 2504-2512.

9. Fernandez LS, Buchanan MS, Carroll AR, Feng YJ, Quinn RJ, Avery VM. Flinderoles A-C: antimalarial bisindole alkaloids from Flindersia species. Org Lett 2009; 11:329-332.

10. $Q u$ J, Fang L, Ren $X D$, Liu Y, Yu SS, Li L, Bao XQ, Zhang $D$, Li Y, Ma SG. Bisindole alkaloids with neural anti-inflammatory activity from Gelsemium elegans. J Nat Prod 2013; 76: 2203-2209.

11. Van Beek TA, Verpoorte $R$, Svendsen $A B$, Fokkens $R$. Antimicrobially active alkaloids from Tabernaemontana chippii. J Nat Prod 1985; 48: 400-423.

12. Kong $L M$, Feng $T$, Wang $Y Y, L i X Y$, Ye ZN, An T, Qing $C$, Luo XD, Li Y. Bisleuconothine A, a bisindole alkaloid, inhibits colorectal cancer cell in vitro and in vivo targeting Wnt signaling. Oncotarget 2016; 7(9): 10203 10214.

13. Lina TT, Luo T, Velayutham TS, Das S, McBride JW. Ehrlichia Activation of Wnt-PI3K-mTOR Signaling Inhibits Autolysosome Generation and Autophagic Destruction by the Mononuclear Phagocyte. Infect Immun 2017; 85(12): e00690-17.

14. Guide for the Care and Use of Laboratory Animals: Eighth Edition Committee for the Update of the Guide for the Care and Use of Laboratory Animals; National Research Council. 2010; ISBN: 0-309-15401-4.

15. Eriksson K, Lönnblom E, Tour G, Kats A, Mydel P, Georgsson $P$, Hultgren $C$, Kharlamova $N$, Norin $U$, Jönsson J, Lundmark A, Hellvard A, Lundberg $K$, Jansson L, Holmdahl R, Yucel-Lindberg T. Effects by periodontitis on pristane-induced arthritis in rats. $J$ Transl Med. 2016; 14(1): 311. 
16. Silva N, Abusleme L, Bravo D, Dutzan N, Garcia-Sesnich J, Vernal R, Hernández M, Gamonal J. Host response mechanisms in periodontal diseases. J Appl Oral Sci 2015; 23(3): 329-355.

17. Hajishengallis G. Periodontitis: from microbial immune subversion to systemic inflammation. Nat Rev Immunol 2015; 15(1): 30-44.

18. Nanjundaiah SM, Astry B, Moudgil KD. Mediators of inflammation-induced bone damage in arthritis and their control by herbal products. Evid Based Complement Alternat Med 2013; 2013: 518094.
19. Yu XJ, Xiao CJ, Du YM, Liu S, Du Y, Li S. Effect of hypoxia on the expression of RANKL/OPG in human periodontal ligament cells in vitro. Int J Clin Exp Pathol 2015; 8(10): 12929-12935.

20. Bhuvaneswarri J, Gita B, Chandrasekaran SC. Detection of rankl positive cells in gingival tissue in healthy \& chronic periodontal disease patients-a comparative study. J Clin Diagn Res 2014; 8(11): ZC31-ZC34.

21. Wang $Y$, Andrukhov O, Rausch-Fan X. Oxidative Stress and Antioxidant System in Periodontitis. Front Physiol 2017; 8: 910. 